\title{
Regulation of Autotrophic Metabolism in Pseudomonas oxalaticus OX1 Wild-type and an Isocitrate-lyase-deficient Mutant
}

\author{
By W. G. MEIJER AND L. DIJKHUIZEN* \\ Department of Microbiology, University of Groningen, Kerklaan 30, 9751 NN Haren, \\ The Netherlands
}

(Received 11 April 1988; revised 10 August 1988)

\begin{abstract}
In Pseudomonas oxalaticus the activity and synthesis of the Calvin cycle enzyme ribulose-1,5bisphosphate carboxylase/oxygenase (RuBisCO) are regulated by inactivation and endproduct repression, respectively. Phosphoenolpyruvate (PEP) has been suggested to function as a signal molecule for the latter control system. During growth of the organism in carbon-source-limited continuous cultures with various ratios of acetate and formate in the feed, the RuBisCO levels varied considerably, but no correlation was observed with the intracellular concentrations of PEP. To study whether the repression exerted by acetate utilization was dependent on the synthesis of glycolytic intermodiates from this compound, an acetate-negative mutant defective in isocitrate lyase was isolated and characterized. Clear evidence was obtained that in this mutant acetate is as effective in repressing $\mathrm{RuBis} \mathrm{CO}$ synthesis as in the wild-type. It therefore appears more likely that acetyl-COA or a closely related metabolite functions as a signal molecule in the regulation of RuBisCO synthesis.
\end{abstract}

\section{INTRODUCTION}

In the facultative autotroph Pseudomonas oxalaticus OX1 the synthesis of RuBisCO, the key enzyme in the Calvin cycle of $\mathrm{CO}_{2}$ fixation, is highly regulated. During growth of the organism on formate, a substrate which is oxidized to $\mathrm{CO}_{2}$ by formate dehydrogenases, large amounts of RuBisCO are synthesized. During growth in batch cultures on substrates which allow a rapid, heterotrophic growth mode (e.g. acetate), no enzyme activity is detectable. Addition of formate to the latter cultures results in its utilization as an ancillary energy source, but not in the synthesis of RuBisCO (Dijkhuizen et al., 1978).

When $P$. oxalaticus is grown on a mixture of formate and acetate in carbon-limited continuous cultures, repression of RuBisCO synthesis is less severe, and dependent on the ratio of the two substrates in the feed and the dilution rate (Dijkhuizen \& Harder, 1979). To explain these phenomena, it was suggested that the synthesis of RuBisCO in $P$. oxalaticus is regulated via an endproduct repression mechanism in which an intermediate of the central metabolism of the cell may function as a signal molecule (Dijkhuizen \& Harder, 1984). Similar conclusions were reached in studies on other facultatively autotrophic bacteria (Bowien et al., 1987; Tabita, 1988).

Further evidence for the identity of the signal moleculo involved was obtained in experiments with the hydrogen bacterium Alcaligenes eutrophus (Reutz et al., 1982; Im \& Friedrich, 1983). This organism metabolizes fructose via the Entner-Doudoroff pathway. Following the introduction of metabolic blocks in the glycolytic part of the Entner-Doudoroff pathway, cells of the organism incubated in fructose mineral medium possessed $\mathrm{RuBis} \mathrm{CO}$ at levels equivalent

\footnotetext{
Abbreviations: ICL, inocitrate lyase; RuBiaCO, ribuloce-1,5-bisphosphate carboxylase/oxyzenase; PEP, phosphoenclpyruvate.
} 
to those normally encountered only in autotrophically grown cells. A reduced ability to convert fructose into 2-phosphoglycerate and PEP, metabolites which may be considered as endproducts of the Calvin cycle, thus appeared to result in a release of feedback repression in $A$. eutrophus. The degree of repression was proposed to be correlated with the intracellular concentration of PEP.

It was the objective of the present study to obtain more detailed information about the regulation of autotrophic $\mathrm{CO}_{2}$ fixation in $P$. oxalaticus by acetate. Assimilation of acetate via the glyoxylate cycle results in the production of glycolytic intermediates such as PEP. The observed regulation of $\mathrm{RuBisCO}$ synthesis in cells growing in the presence of acetate thus might depend on the intracellular levels of this signal molecule.

\section{METHODS}

Organism and growth conditions. Pseudomonas oxalaticus $\mathrm{OX} 1$ wild-type, its maintenance and the mineral salts media used in batch and continuous cultures have been described previously (Dijkhuizen \& Harder, 1975; Dijkhuizen et al., 1977), as have the experimental conditions of growth on single and mixed substrates in batch (Dijkhuizen et al., 1978) and continuous cultures (Dijkhuizen et al., 1977; Dijkhuizen \& Harder, 1979). During growth on formate in a batch fermenter with a working volume of 3 litres, the $\mathrm{pH}$ was kept constant by automatic titration with formic acid $(25 \%$, w/v) (Knight et al., 1978).

Preparation of cell-free extracts and enzyme assays. Cell-free extracts were prepared according to Dijkhuizen et al. (1978). Enzyme measurements were made in a Hitachi model $100-60$ spectrophotometer at $30^{\circ} \mathrm{C}$. In all assays the observed rate was linear for at least $3 \mathrm{~min}$ and was proportional to the amount of cell-free extract added. The following enzymes were assayed according to published procedures: isocitrate lyase, EC 4.1.3.1 (Dixon \& Kornberg, 1959); ribulose-1,5-bisphosphate carboxylase, EC 4.1.1.39, and NAD-dependent formate dehydrogenase, EC 1.2.1.2 (Dijkhuizen et al., 1978); isocitrate dehydrogenase (NADP-dependent), EC 1.1.1.42 (Levering \& Dijkhuizen, 1985). Citrate synthase, EC 4.1.3.7, was assayed at $412 \mathrm{~nm}$ by following the rate of reduction of 5,5'-dithiobis-(2-nitro-benzoate) (DTNB) in the presence of acetyl-CoA and oxaloacetate (Srere, 1969). The reaction mixture ( $1 \mathrm{ml})$ contained: Tris/HCl buffer, $\mathrm{pH} 8 \cdot 0,50 \mu \mathrm{mol}$; DTNB, $0.1 \mu \mathrm{mol}$; acetyl-CoA, $0.3 \mu \mathrm{mol}$; and extract. The endogenous rate of DTNB reduction, due to the presence of acetyl-CoA deacylase activity was followed for $3 \mathrm{~min}$. The reaction was started by the addition of $1 \mu \mathrm{mol}$ oxaloacetate. The molar extinction coefficient of DTNB at $412 \mathrm{~nm}$ was taken as $13.6 \times 10^{3} \mathrm{l} \mathrm{mol}^{-1} \mathrm{~cm}^{-1}$.

Determination of intracellular PEP concentrations. The methods used for rapid sampling of cells from continuous cultures, extraction of metabolites and the pyruvate-kinase-dependent conversion of PEP and ADP into pyruvate and ATP are those described by Otto (1984). The amount of ATP formed was determined according to Otto et al. (1984), using the luciferine-luciferase system and measuring the ATP-dependent light emission in an Aminco Chem Glow Photometer. The reaction mixture $(200 \mu \mathrm{l})$ contained (final concentrations): $50 \mathrm{mM}$-Tris/acetate, pH 7.75; $1.5 \mathrm{~mm}$-EDTA; $0.075 \%$ (w/v) bovine serum albumin; $10 \mathrm{mM}$-magnesium acetate; $35 \mu \mathrm{M}$-luciferine and 5000 units luciferase (Boehringer Mannheim). Duplicate samples were taken from at least two individual steady states at each ratio of acetate and formate in the feed. The PEP levels in each sample were measured in triplicate. At each ratio of acetate and formate in the feed less than $10 \%$ variation was observed in the PEP levels in the separate samples.

Isolation of acetate-negative mutants. Transposon mutagenesis was carried out using a $P$. oxalaticus wild-type strain carrying plasmid pNJ5000: $: \mathrm{Tn} 7$. This vector can be stably maintained only in recombination-deficient strains and during growth in the presence of the antibiotics tetracycline $(15 \mu \mathrm{g} \mathrm{ml}-1)$ and trimethoprim $(20 \mu \mathrm{g}$ $\mathrm{ml}^{-1}$ ), selecting for the resistance markers coded for by the plasmid and transposon, respectively (Grinter, 1983). Mutants were induced by growing this strain in the absence of antibiotics in fructose mineral medium for $48 \mathrm{~h}$. The cells were subsequently harvested by centrifugation, washed once and diluted 100-fold in mineral medium without carbon source. After $24 \mathrm{~h}$ starvation, acetate $(10 \mathrm{mM})$ and ampicillin $\left(50 \mu \mathrm{g} \mathrm{ml} l^{-1}\right)$ were added to selectively kill cells able to grow on acetate. After $12 \mathrm{~h}$ incubation the cells were harvested, thoroughly washed, and grown in fructose mineral medium followed by a second, identical enrichment cycle. Samples were plated out on fructose mineral agar containing trimethoprim and acetate-negative mutants selected by replica plating of the colonies obtained on acetate agar.

Other analytical methods. The maximum capacity of washed cell suspensions to oxidize formate and acetate $\left(Q_{\mathrm{O}_{2}}^{\mathrm{max}}\right)$ was determined according to Dijkhuizen \& Harder (1975). Protein concentrations were determined by the Lowry method using bovine serum albumin as a standard. Culture dry weight values were determined with a Total Carbon Analyzer (Beckman, model 915A), connected to an Infrared Analyzer (Beckman, model 865). 


\section{RESULTS}

Transition from autotrophic to heterotrophic growth conditions

The effects of acetate on the autotrophic potential of $P$. oxalaticus were studied in more detail by transferring a formate-limited continuous culture of the organism to acetate-limiting conditions (Fig. 1). The transition from autotrophic to heterotrophic growth proceeded smoothly, without accumulation of acetate, and after one to two volume changes the culture slowly reached a new steady state (Fig. $1 a$ ). In the early hours of the experiment the isocitrate lyase (ICL) activity rapidly increased from a low basal level. In the same period the citrate synthase activity more than doubled, reflecting the more important role of the tricarboxylic acid cycle in energy generation during growth on acetate than on formate. The isocitrate dehydrogenase activity on the other hand strongly fluctuated during the adaptation period, but remained on average at the same level (Fig. 1b). Interestingly, the activities of the NADdependent formate dehydrogenase and RuBisCO (Fig. 1a) decreased rapidly following the substrate transition. After correcting the data for the changes that occurred in cell density, it became clear that the drop in the activities of these enzymes was in fact considerably faster than the wash-out rate. It therefore has to be concluded that under these conditions the enzymes became inactivated.

\section{Intracellular levels of PEP duiring steady state growth conditions}

A possible direct involvement of PEP in the control of RuBisCO synthesis was studied by measuring the intracellular levels of this metabolite in P. oxalaticus, grown under steady state conditions in chemostat cultures. As reported previously (Dijkhuizen \& Harder, 1979), the synthesis of $\mathrm{RuBisCO}$ in this organism became increasingly repressed when the acetate/formate ratios in the feed were increased (Table 1). Addition of acetate stimulated the synthesis of ICL, allowing assimilation of this $\mathrm{C}_{2}$ compound via the glyoxylate cycle, thus resulting in increased biomass levels. No significant changes in the intracellular concentrations of PEP, however, were observed under these carbon-limiting steady state conditions. This was not even the case when the organism was grown on acetate alone, which resulted in a complete switch-off of RuBisCO synthesis (Table 1). On the basis of these observations it became unlikely that PEP functioned directly as a signal molecule in the regulation of $\mathrm{RuBisCO}$ synthesis. This raised the question whether the repression exerted by acetate metabolism on RuBisCO synthesis was dependent on its assimilation via the glyoxylate cycle, resulting in generation of oxaloacetate and glycolytic intermediates.

\section{Isolation of isocitrate-lyase-negative mutants}

After transposon mutagenesis 2000 trimethoprim resistant colonies were tested, seven of which were unable to grow on acetate agar, but had retained their ability to grow on fructose, lactate, succinate or formate. We subsequently observed that lactate-grown cells of wild-type $P$. oxalaticus possessed ICL activity [ $45 \mathrm{nmol} \mathrm{min}^{-1}$ (mg protein) ${ }^{-1}$ ], although the enzyme is not required for growth on this substrate. Following growth on lactate three of the acetate-negative strains were found to be affected in ICL synthesis. One of these mutants, strain ACE 3, turned out to be very stable and completely lacked ICL activity. This strain, which was still able to oxidize acetate when this compound was added to cultures growing exponentially on fructose (data not shown), was selected for further studies.

\section{Growth of strain $A C E 3$ on acetate plus formate}

Initially, we considered it theoretically possible that an ICL-negative strain would be able to grow autotrophically on acetate, by combining energy generation from acetate and $\mathrm{CO}_{2}$ assimilation via the Calvin cycle. Acetate-negative mutants such as strain ACE 3, however, could be isolated in a straight-forward manner. Incubation of fructose-pregrown cells of strain ACE 3 in acetate $(10 \mathrm{~mm})$ medium nevertheless resulted in a linear increase in the optical density of the culture, with a doubling time of $20 \mathrm{~h}$ (data not shown). No evidence could be obtained that this was based on autotrophic $\mathrm{CO}_{2}$ fixation as the activity of $\mathrm{RuBisCO}$ (and ICL) 


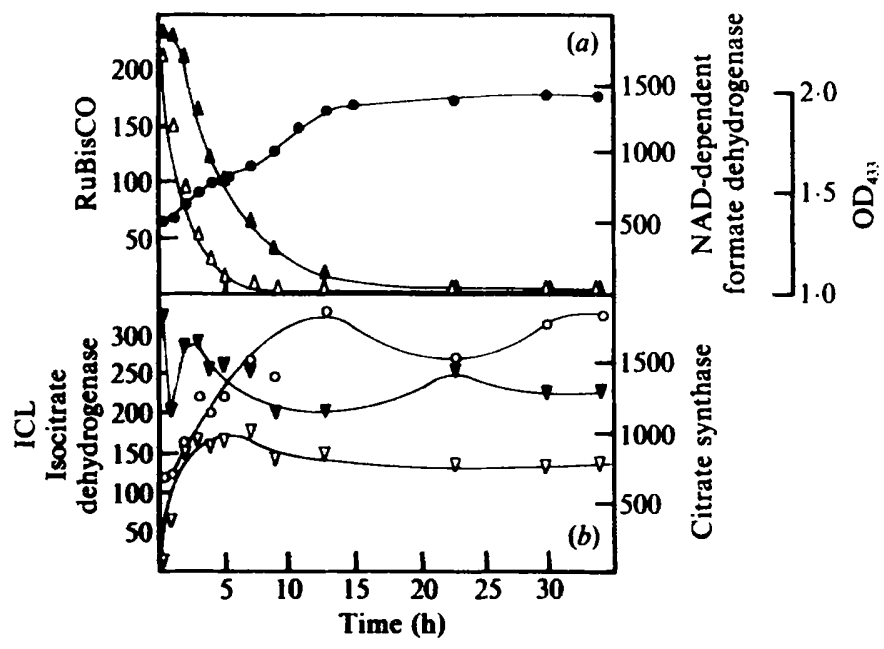

Fig. 1. Transition of formate-limited $\left(S_{\mathrm{R}}=100 \mathrm{~mm} ; D=0.10 \mathrm{~h}^{-1}\right)$ cells of $P$. oxalaticus $\mathrm{OX} 1$ to acetatelimiting $\left(S_{\mathrm{R}}=30 \mathrm{mM} ; D=0.10 \mathrm{~h}^{-1}\right)$ growth conditions. (a) Optical density (O); NAD-dependent formate dehydrogenase $(\triangle)$; RuBisCO $(\Lambda)$. (b) ICL $(\nabla)$; isocitrate dehydrogenase $(\nabla)$; citrate synthase $(\mathrm{O})$. Enzyme activities are given as $\mathrm{nmol} \mathrm{min}^{-1}$ (mg protein) ${ }^{-1}$.

Table 1. Enzyme activities, dry wt values and intracellular PEP values in $P$. oxalaticus $O X 1$

$P$. oxalaticus was grown on formate and acetate in carbon-source-limited culture at $D=0 \cdot 10 \mathrm{~h}^{-1}$.

Substrate concentration in feed (mM)

$\begin{array}{ccc}\text { Formate } & \text { Acetate } & \begin{array}{c}\text { Dry wt } \\ \left(\mathrm{mg} \mathrm{l}^{-1}\right)\end{array} \\ 100 & 0 & 365 \\ 100 & 5 & 515 \\ 100 & 10 & 640 \\ 0 & 30 & 645\end{array}$

$\begin{array}{ccc}\begin{array}{c}\text { RuBisCo } \\ \text { [nmol min }\end{array} & \begin{array}{c}\text { ICL } \\ \text { (mg protein) }\end{array}{ }^{-1} \text { ] } & \begin{array}{c}\text { PEP } \\ \text { [nmol (mg protein) })^{-1} \text { ] }\end{array} \\ 220 & 0 & 2 \cdot 5 \\ 120 & 60 & 2 \cdot 9 \\ 95 & 120 & 2 \cdot 9 \\ 0 & 150 & 3 \cdot 1\end{array}$

remained undetectable [ $\left.<5 \mathrm{nmol} \mathrm{min} \mathrm{(mg} \mathrm{protein})^{-1}\right]$. This phenomenon instead appeared to be due to the synthesis from acetate of considerable amounts of storage material, which was identified as polyhydroxybutyrate (data not shown).

The initial characterization of strain ACE 3 showed that it was not affected in formate metabolism, displaying the normal growth rate on formate alone (doubling time $3.5 \mathrm{~h}$ ). On a mixture of acetate $(10 \mathrm{mM})$ plus formate $(15 \mathrm{mM})$ it nevertheless behaved as described above for acetate alone. Again a linear increase in optical density (doubling time $20 \mathrm{~h}$ ) was observed, and not only ICL but also RuBisCO and formate dehydrogenase activities remained undetectable (data not shown). These observations suggested that in strain ACE 3 acetate was still able to repress the synthesis of the autotrophic enzymes. Clear confirmation for this was subsequently obtained in experiments with formate-pregrown cells of strain ACE 3 and, for comparison, wild-type $P$. oxalaticus (Figs 2 and 3). Addition of a pulse of acetate (5 mM) to a mid-exponential phase culture of the wild-type strain growing on formate $(15 \mathrm{mM})$ resulted in a decrease in the doubling time from 3.4 to $2.5 \mathrm{~h}$ (Fig. 2). The $Q_{\mathrm{O}_{2}}^{\max }$-acetate and the ICL activities increased almost immediately, whereas the $Q_{\mathrm{O}_{2}}^{\max }$-formate and $\mathrm{RuBisCO}$ activities dropped gradually. The levels of isocitrate dehydrogenase remained approximately constant. In a similar experiment with strain ACE 3, no change in growth rate was apparent following acetate addition (Fig. 3). In this mutant ICL activity remained undetectable throughout the experiment and only relatively low levels of the $Q_{\mathrm{O}_{2}}^{\max }$-acetate were observed. Whereas the $Q_{\mathrm{O}_{2}}^{\max }$-formate and isocitrate 


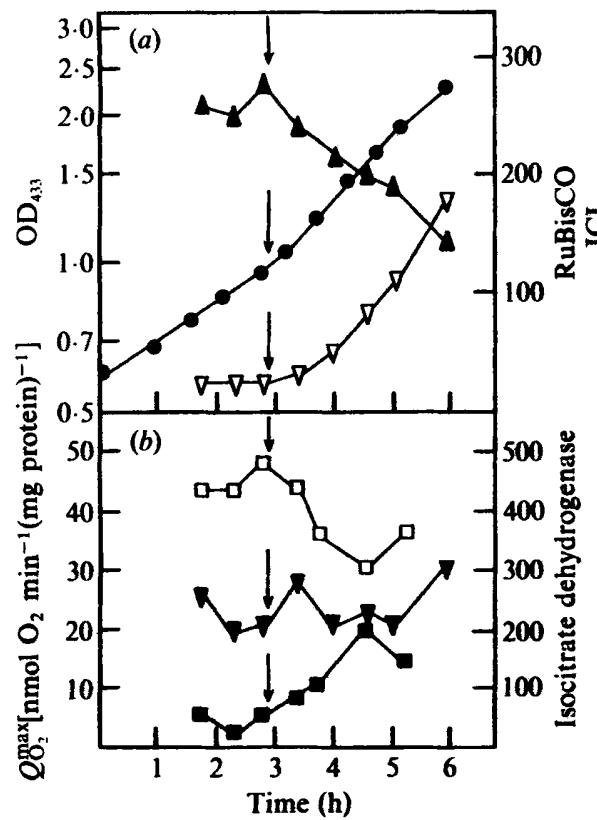

Fig. 2

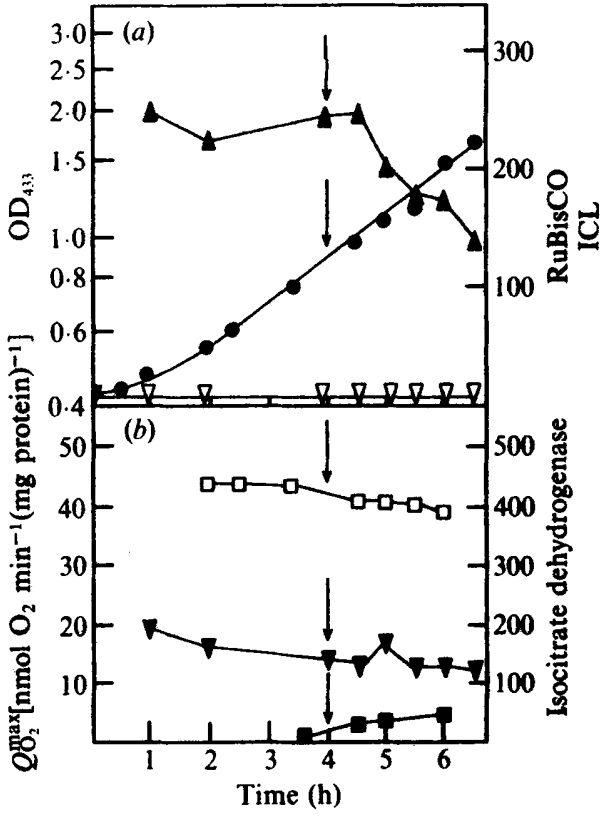

Fig. 3

Fig. 2. Growth of $P$. oxalaticus $\mathrm{OX} 1$ wild-type on formate $(15 \mathrm{mM} ; \mathrm{pH}$ control by automatic titration with formic acid, $25 \%$, w/v), and the effects of a pulsed addition (arrow) of acetate ( $5 \mathrm{mM}$ ). (a) Optical density (O); RuBisCO (A); ICL $(\nabla)$. (b) $Q_{O_{2}}^{\max }$-acetate ( $)$; $Q_{O_{2}}^{\max }$-formate ( $\left.\square\right)$; isocitrate dehydrogenase $(\nabla)$. Enzyme activities are given as $\mathrm{nmol} \mathrm{min}^{-1}$ (mg protein) ${ }^{-1}$.

Fig. 3. Growth of the ICL-negative mutant strain ACE 3 on formate (15 mM; pH control by automatic titration with formic acid, $25 \%, \mathrm{w} / \mathrm{v}$ ), and the effects of a pulsed addition (arrow) of acetate $(5 \mathrm{~mm}) .(\mathrm{a})$ Optical density (O); RuBisCO $\left(\mathcal{N}\right.$; ICL $(\nabla)$. (b) $Q_{\mathrm{O}_{2}}^{\max }$-acetate $(\square) ; Q_{\mathrm{O}_{2}}^{\max }$-formate ( $\left.\square\right)$; isocitrate dehydrogenase $(\nabla)$. Enzyme activities are given as nmol min $^{-1}$ (mg protein) ${ }^{-1}$.

dehydrogenase activity hardly changed at all, the $\mathrm{RuBisCO}$ activities decreased rapidly. Under these batch culture conditions, with a controlled supply of formic acid as the titrant for $\mathrm{pH}$ regulation, inactivation of $\mathrm{RuBisCO}$ was not evident with either strain. From the data obtained it could be calculated that in both organisms RuBisCO synthesis became repressed completely following acetate addition, i.e. that the decrease in RuBisCO activities could be explained by a redistribution of existing enzyme over newly synthesized cells. It is concluded that in strain ACE 3, which is unable to convert acetate into glycolytic intermediates, the synthesis of $\mathrm{RuBisCO}$ is as sensitive to repression by acetate as in the wild-type organism.

\section{DISCUSSION}

Growth of $\boldsymbol{P}$. oxalaticus on mixtures of acetate and formate in batch cultures results in a complete switch-off of the energetically expensive $\mathrm{CO}_{2}$ fixation (Dijkhuizen et al., 1978). In the present study it became clear that, in addition to regulation via repression of enzyme synthesis, the organism also has a mechanism for rapid inactivation of $\mathrm{RuBisCO}$ under conditions where its presence is no longer required (Fig. 1). In substrate transition experiments with Thiobacillus versutus (Gottschal et al., 1981), RuBisCO inactivation was shown to occur via proteolytic degradation of the enzyme. Recently, Mann \& Turner (1987) provided preliminary evidence that $\mathrm{RuBisCO}$ activity in Rhodomicrobium vannielii is regulated via (de)phosphorylation. The precise mechanism involved in $P$. oxalaticus requires further investigation.

The physiological evidence available suggested that, as is the case for other biosynthetic pathways, synthesis of the enzymes of autotrophic $\mathrm{CO}_{2}$ fixation is controlled by the intracellular 
levels of endproducts of the Calvin cycle, with PEP being the strongest candidate for such a signal molecule function (Reutz et al., 1982; Dijkhuizen \& Harder, 1984). No correlation, however, was observed between RuBisCO and PEP levels (Table 1). This made it unlikely that PEP functioned directly as a signal molecule. The subsequent isolation of ICL-negative mutants allowed us to assess whether the repressive effect exerted by acetate in $P$. oxalaticus in fact was dependent on its conversion into oxaloacetate (and PEP) via the glyoxylate cycle. The theoretical possibility that in such a mutant energy generation from acetate oxidation could now serve to drive autotrophic $\mathrm{CO}_{2}$ fixation was tested but no evidence for this could be obtained. This might have been due to the fact that autotrophic $\mathrm{CO}_{2}$ fixation requires a higher rate of energy generation than could be sustained by acetate alone in the mutant. We therefore attempted to stimulate energy generation by incubating strain ACE 3 in the presence of both acetate and formate. Again, no RuBisCO synthesis occurred and although strain ACE 3 was still able to grow on formate alone with a doubling time of $3.5 \mathrm{~h}$, no stimulation of growth could be observed following formate addition.

An analysis of the effects of pulsed addition of acetate to cultures of strain ACE 3 and the wild-type in the mid-exponential phase of growth on formate subsequently made it clear that in the mutant strain acetate is as strong a source of repression of $\mathrm{RuBisCO}$ synthesis as in the wildtype (Figs 2 and 3). On the basis of these observations it is considered more likely that acetylCoA, or a metabolite derived from it, is involved as a signal molecule for the regulation of the synthesis of RuBisCO.

The investigations were supported (in part) by the Foundation for Fundamental Biological Research (BION) which is subsidized by the Netherlands Scientific Organization (NWO). Thanks are due to Professor W. Harder for valuable discussions.

\section{REFERENCES}

Bowien, B., Husemann, M., KLINTWORTh, R. \& WINDHOVEL, U. (1987). Metabolic and molecular regulation of the $\mathrm{CO}_{2}$-assimilating enzyme system in aerobic chemoautotrophs. In Microbial Growth on $C_{1}$ Compounds, pp. 21-27. Edited by H. W. van Verseveld \& J. A. Duine. Dordrecht, The Netherlands: Martinus Nijhoff.

DuKhuizen, L. \& HARDER, W. (1975). Substrate inhibition in Pseudomonas oxalaticus OX1: a kinetic study of growth inhibition by oxalate and formate using extended cultures. Antonie van Leetwenhoek 41, 135-146.

DIJKHUIzeN, L. \& HARder, W. (1979). Regulation of autotrophic and heterotrophic metabolism in Pseudomonas oxalaticus OX1. Growth on mixtures of acetate and formate in continuous culture. Archives of Microbiology 123, 47-53.

DukhuIzen, L. \& HARDER, W. (1984). Current views on the regulation of autotrophic carbon dioxide fixation via the Calvin cycle in bacteria. Antonie van Leeuwenhoek 50, 473-487.

DiJKhUIZEN, L., Wiersma, M. \& HARder, W. (1977). Energy production and growth of Pseudomonas oxalaticus on oxalate and formate. Archives of Microbiology 115, 229-236.

DirkHUizen, L., KNIGH, M. \& HARDER, W. (1978). Metabolic regulation in Pseudomonas oxalaticus OX1. Autotrophic and heterotrophic growth on mixed substrates. Archives of Microbiology 116, $77-83$.

Dixon, G. H. \& Kornmerg, H. L. (1959). Assay methods for key enzymes of the glyoxylate cycle. Biochemical Journal 72, 3p.
GotTschal, J. C., Pol, A. \& Kuenen, J. G. (1981). Metabolic flexibility of Thiobacillus A2 during substrate transitions in the chemostat. Archives of Microbiology 129, 23-28.

Grinter, N. J. (1983). A broad-host-range cloning vector transposable to various replicons. Gene 21, 133-143.

IM, D. \& FRIEDRICH, C. G. (1983). Fluoride, hydrogen and formate activate ribulose bisphosphate carboxylase formation in Alcaligenes eutrophus. Journal of Bacteriology 154, 803-808.

Knight, M., Dukhuizen, L. \& Harder, W. (1978). Metabolic regulation in Pseudomonas oxalaticus OX1. Enzyme and coenzyme concentration changes during substrate transition experiments. Archives of Microbiology 116, 85-90.

LeVERING, P. R. \& DiJkhuizen, L. (1985). Regulation of methylotrophic and heterotrophic metabolism in Arthrobacter P1. Growth on mixtures of methylamine and acetate in batch and continuous cultures. Archives of Microbiology 142, 113-120.

ManN, N. H. \& TURner, A. M. (1987). Protein phosphorylation and the control of autotrophic metabolism in Rhodomicrobium vannielii. In Abstracts Lithoautotrophy, a Centenary Meeting in Memory of S. N. Winogradsky, p. 33. Göttingen, FRG.

OTTO, R. (1984). Uncoupling of growth and acid production in Streptococcus cremoris. Archives of Microbiology 140, 225-230.

OTTO, R., KLONT, B., TEN BRINK, B. \& KonINGs, W. N. (1984). The phosphate potential, adenylate energy charge and proton motive force in growing cells of 
Streptococcus cremoris. Archives of Microbiology 139, SRERE, P. A. (1969). Citrate synthase. Methods in 338-343. Enzymology 13, 3-11.

REUTZ, I., SCHOBERT, P. \& BOWIEN, B. (1982). Effect of TABITA, F. R. (1988). Molecular and cellular regulation phosphoglycerate mutase deficiency on heterotrophic and autotrophic carbon metabolism of Alcaligenes eutrophus. Journal of Bacteriology 151, of autotrophic carbon dioxide fixation in microorganisms. Microbiological Reviews 52, 155-189. 8-14. 